\title{
Multi-sequence non-contrast MRI characterization of deep vein thrombosis in man
}

\author{
Alkystis Phinikaridou ${ }^{1 *}$, Prakash Saha ${ }^{2}$, Marcelo E Andia ${ }^{3,1}$, Alberto Smith², Rene Botnar ${ }^{1}$ \\ From 18th Annual SCMR Scientific Sessions \\ Nice, France. 4-7 February 2015
}

\section{Background}

Deep vein thrombosis (DVT) remains an important medical condition. The biophysical characteristics of thrombus may determine the response to endovascular interventions. We demonstrated that multi-sequence thrombus imaging (MSTI) using magnetization transfer rate (MTR), apparent diffusion coefficient (ADC) and T1 mapping can characterize thrombus organization and identify thrombi amenable to thrombolysis in a murine model. Here, we investigate whether MSTI can be translated to man and how these measurements associate with the outcome of intervention.

\section{Methods}

MSTI was performed in patients with ilio-femoral DVT undergoing lysis at 3T using a 32-channel coil. T2-prepared, bSSFP MR venography (MRV) was acquired with: $\mathrm{TR} / \mathrm{TE}=4.2 / 2.1 \mathrm{~ms}$, flip angle $=700, \mathrm{FOV}=220 \times 299 \times 200 \mathrm{~mm}$, matrix $=112 \times 148$, slice thickness $=2 \mathrm{~mm}$, resolution $=$ $2 \times 2 \mathrm{~mm}$, averages $=1, T 2$-prep-echo-time $=30 \mathrm{~ms}$. 3D T1-weighted spoiled-GRE images were acquired with and without an on-resonance MT pre-pulse with: TR/TE $=69$ / $2.2 \mathrm{~ms}$, flip angle $=180, \mathrm{FOV}=220 \times 299 \times 198 \mathrm{~mm}$, matrix $=$ $112 \times 148$, slice thickness $=6 \mathrm{~mm}$, resolution $=2 \times 2 \mathrm{~mm}$, averages $=1$. The binomial-block MT pre-pulse had a

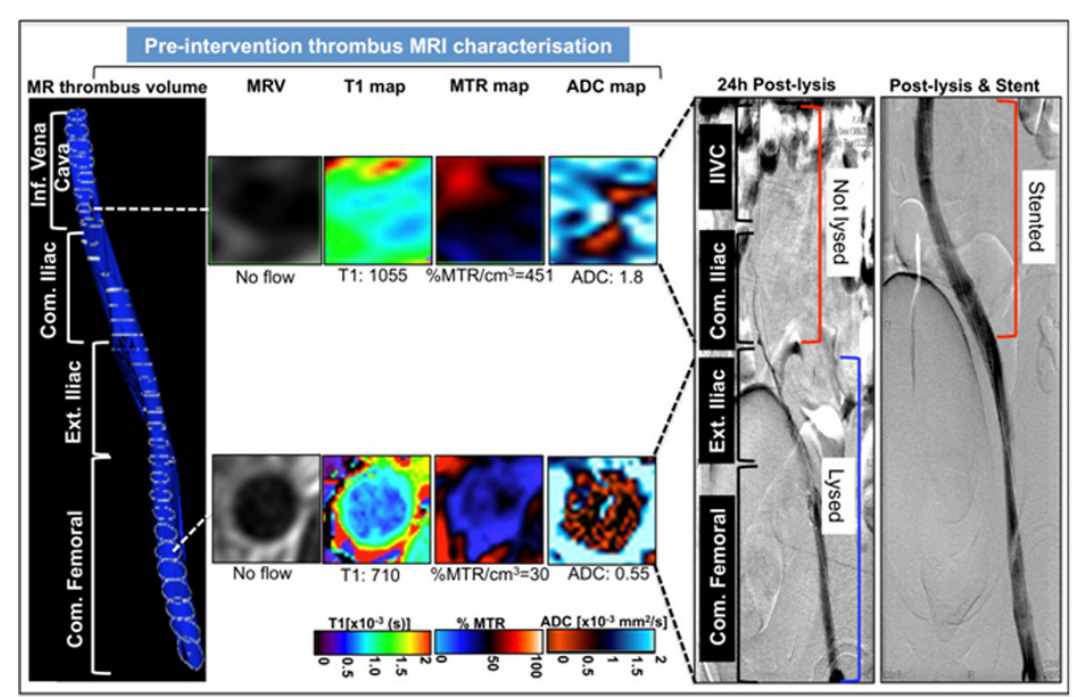

Figure 1 In vivo multi-sequence thrombus imaging.

'Biomedical Egineering, King's College London, London, UK

Full list of author information is available at the end of the article 
duration $=1.92 \mathrm{~ms}$ and repetitions $=1.2 \mathrm{D}$ diffusion weighted spin-echo images were acquired with: $\mathrm{TR} / \mathrm{TE}=1780 / 82 \mathrm{~ms}$, flip angle $=900$, diffusion-echo-time $=333 \mathrm{~ms}$, FOV= $220 \times 299 \times 125 \mathrm{~mm}$, matrix $=112 \times 148$, slice thickness $=10 \mathrm{~mm}$, resolution $=2 \times 2 \mathrm{~mm}$, averages $=2$ and $b$-values $=0,333,667$, $1000 \mathrm{~mm}^{2} / \mathrm{s}$. A 2D MOdified Look-Locker Inversion Recovery (MOLLI; 3-3-5) sequence was used for T1 mapping: $T R / T E=3.3 / 1.6 \mathrm{~ms}$, flip angle $=35^{\circ}$. $\mathrm{FOV}=$ $220 \times 299 \times 198 \mathrm{~mm}$, matrix $=112 \times 148$, slice thickness $=6 \mathrm{~mm}$, resolution $=2 \times 2 \mathrm{~mm}$, averages $=1$. Thrombi were segmented on all images using Osirix and the T1, \%MTR/ $/ \mathrm{cm}^{3}$, and $A D C$ values were reported.

\section{Results}

MSTI is feasible in man and successful characterization of ilio-femoral DVT was achieved in 30mins (Fig. 1). Figure 1A shows a volumetric reconstruction of a segmented thrombus that extended from the inferior vena cava (IVC) to the common femoral vein (CFV). Representative images of the segmented thrombus at 2 different levels revealed the structural heterogeneity within the same thrombus (Fig. 1B-1I). The thrombus in the IVC and CIV had a higher T1-relaxation time, MTR/ $\mathrm{cm}^{3}$ and ADC values (Fig. 1C-E) compared to the thrombus in the external iliac (EIV) and common femoral (CFV) veins (Fig. 1F-I). Interestingly, the thrombus in the IVC and CIV did not lyse after $24 \mathrm{~h}$ of thrombolysis, where as the thrombus in the EIV and CFV lysed, as seen on the invasive venogram (Fig. 1J). Recanalization of the thrombus in the IVC and CIV was achieved after stenting (Fig. 1K). Quantitative measurements of all the slices in each vascular segment are illustrated in Fig. 2.

\section{Conclusions}

Non-contrast MSTI, using a combination of MTR, ADC and T1 mapping is feasible in man and may allow characterization of thrombus structure and understanding

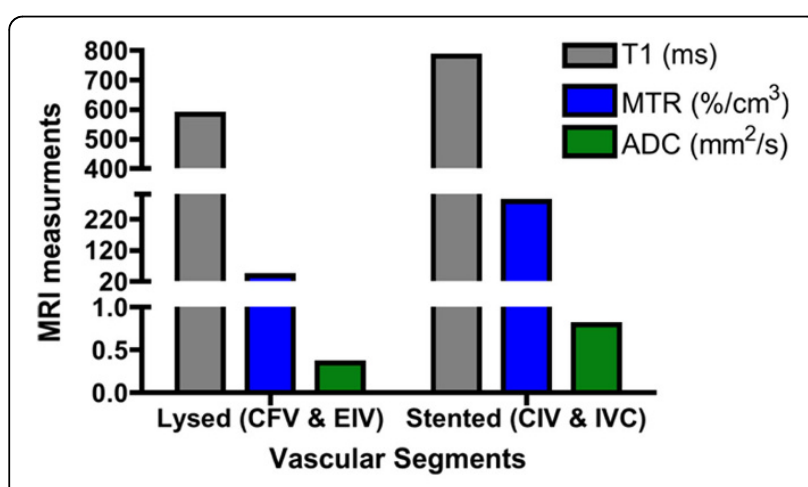

Figure 2 Quantitative MRI measurements differ between lysed and stented vascular segments on how these measurements relate to the outcome of interventions.

\section{Funding}

N/A.

Authors' details

${ }^{1}$ Biomedical Egineering, King's College London, London, UK. ${ }^{2}$ Academic Surgery, King's College London, London, UK. ${ }^{3}$ Radiology, P, Santiago, Chile.

Published: 3 February 2015

doi:10.1186/1532-429X-17-S1-P10

Cite this article as: Phinikaridou et al:: Multi-sequence non-contrast MRI characterization of deep vein thrombosis in man. Journal of

Cardiovascular Magnetic Resonance 2015 17(Suppl 1):P10.
Submit your next manuscript to BioMed Central and take full advantage of:

- Convenient online submission

- Thorough peer review

- No space constraints or color figure charges

- Immediate publication on acceptance

- Inclusion in PubMed, CAS, Scopus and Google Scholar

- Research which is freely available for redistribution
C Biomed Central 